\title{
Redução do nível de proteína bruta em rações para frangos de corte em ambiente de termoneutralidade ${ }^{1}$
}

\section{Will Pereira de Oliveira ${ }^{2}$, Rita Flávia Miranda de Oliveira ${ }^{3}$, Juarez Lopes Donzele ${ }^{3}$, Luiz Fernando Teixeira Albino ${ }^{3}$, Mariana dos Santos Martins ${ }^{4}$, Ana Paula de Assis Maia ${ }^{4}$}

\author{
1 Projeto apoiado pela AJINOMOTO. \\ 2 Programa de Pós-graduação em Zootecnia - Universidade Federal de Viçosa - MG. \\ ${ }^{3}$ Departamento de Zootecnia, Universidade Federal de Viçosa - MG. \\ ${ }^{4}$ Curso de Graduação em Zootecnia, Universidade Federal de Viçosa - MG- PIBIC.
}

RESUMO - O experimento foi realizado para avaliar o efeito da redução do nível de proteína bruta (PB) da ração formulada de acordo com o conceito de proteína ideal e suplementada com aminoácidos industriais, sobre o desempenho e rendimento de cortes de frangos de corte machos de 22 a 42 dias de idade mantidos em ambiente termoneutro. Foram utilizados 280 frangos de corte machos "Cobb" com peso inicial de $856 \pm 6,48 \mathrm{~g}$, distribuídos em delineamento experimental inteiramente casualizado, com cinco tratamentos (21,6; 20,6; 19,6; 18,6 e 17,6\% de PB), oito repetições de sete aves por unidade experimental. A temperatura no interior da sala foi mantida em $21,6 \pm 0,7^{\circ} \mathrm{C}$, a umidade relativa em $74 \pm 4,0 \%$ e a temperatura de globo negro em $22,5 \pm 0,7^{\circ} \mathrm{C}$. O índice de temperatura de globo e umidade (ITGU) calculado para o período foi de $70 \pm 0,9$. Não houve efeito da redução dos níveis de PB sobre o ganho de peso e o consumo de ração, entretanto, a conversão alimentar foi influenciada pela redução dos níveis de PB sendo que as aves alimentadas com a ração que continha 22,0\% de PB apresentaram o melhor resultado. A redução dos níveis de PB não influenciou o peso absoluto de carcaça e os pesos absoluto e relativo de peito, coxa e sobrecoxa. A redução do nível de PB da ração, de 21,6 para 17,6\%, e formulada de acordo com o conceito de proteína ideal piora a conversão alimentar dos frangos de corte mantidos em ambiente termoneutro, não influenciando as demais variáveis estudadas.

Palavras-chave: cortes, desempenho, frangos de corte, proteína ideal, termoneutralidade

\section{Dietary crude protein level reduction for broilers maintained in thermoneutral environment}

\begin{abstract}
The objective of this experiment was to evaluate the effects of dietary crude protein (CP) level reduction of ration formulated according to ideal protein concept and with supplementation of industrial amino acids on the performance and yield of noble cuts of broilers from 22 to 42 days of age kept under thermoneutral conditions. It was used 280 "Cobb" male broilers with initial weight of $856 \pm 6.48 \mathrm{~g}$, distributed in a completely randomized experimental design, with five treatments (21.6; 20.6; 19.6; 18.6 and $17.6 \%$ CP) and eight replications with seven birds per experimental unit. Temperatures inside the rooms were maintained at $21.6 \pm 0.7^{\circ} \mathrm{C}$, relative humidity at $74.4 .0 \%$ and black globe temperature of $22.5 \pm 0.7^{\circ} \mathrm{C}$. Black globe temperature and humidity index (BGHTI) calculated for a period of $70 \pm 0.9$. There was no effect of the reduction of the levels of $\mathrm{CP}$ on weight gain and on feed intake but feed conversion was influenced by the reduction of the CP levels, and the birds fed diet with $22.0 \%$ of CP presented a better result. The reduction of the levels of CP did not influence absolute carcass weight and absolute and relative weights of breast, thigh and drumstick. Reduction of the level of dietary CP from 21.6 to $17.6 \%$ and formulated according to ideal protein concept worsens feed conversion of broilers kept in thermoneutral environment, not influencing the other studied variables.
\end{abstract}

Key Words: broilers, cuts, ideal protein, performance, thermoneutrality

\section{Introdução}

As linhagens de frangos de corte de alto desempenho, com melhor eficiência de digestão e absorção de nutrientes, maior taxa de crescimento corporal e elevado potencial de deposição de carne na carcaça (Albino et al., 1999;
Siqueira et al., 2007). O maior crescimento está, no entanto, associado ao elevado custo energético e ao aumento da produção de calor metabólico, tornando as aves mais sensíveis às flutuações térmicas (Macari, 2001). Todavia, quando mantidas em ambiente livre de estresse térmico e com adequado consumo de nutrientes, 
as aves podem expressar seu máximo potencial para produção.

Entre os nutrientes da ração, a proteína é o principal a ser depositado na carcaça como tecido muscular, influenciando a conversão alimentar, a qualidade da carcaça e o ganho de peso das aves (Suida, 2001). Contudo, quando fornecida em excesso ou desbalanceada na ração, pode comprometer o desempenho das aves por promover excesso de aminoácidos na circulação sanguínea, que, para serem metabolizados gastam energia extra (Aletor et al., 2000).

$\mathrm{O}$ excesso de nitrogênio eliminado nas excretas, apresenta elevado potencial poluidor do ambiente, o que é agravado pela grande quantidade de dejetos gerados pela produção animal. Uma forma de reduzir esse efeito consiste na redução da carga de nutrientes excretados pelos animais (Mendonza et al., 2001; Silva et al., 2006).

A utilização do conceito de proteína ideal na formulação das rações, tem possibilitado o fornecimento de níveis de aminoácidos mais adequados às exigências dos frangos, diminuindo as perdas de nitrogênio pelas excretas (Deschepper \& De Groote, 1995; Corzo et al., 2005). Essa prática está associada à redução do teor de proteína bruta da ração e suplementação com aminoácidos industriais. Contudo, informações sobre o quanto a proteína bruta da ração pode ser reduzida e seus efeitos sobre o desempenho de frangos não estão esclarecidas. Enquanto alguns autores (Deschepper \& De Groote, 1995; Aletor et al., 2000; Faria Filho, 2003 e 2006) têm comprovado que a redução do teor de proteína bruta das rações suplementadas com aminoácidos industriais não altera o desempenho e as características de carcaça de frangos e ainda reduz a excreção de nitrogênio, outros (Alleman \& Leclercq, 1997; Temim et al., 2000; Sabino et al., 2004) têm verificado piora no desempenho e baixo rendimento.

Diante desse contexto, o estudo foi realizado para avaliar os efeitos da redução do nível de proteína bruta da ração formulada de acordo com o conceito de proteína ideal e suplementada com aminoácidos industriais sobre o desempenho e o rendimento de carcaça de frangos de corte machos em fase de crescimento mantidos em ambiente termoneutro.

\section{Material e Métodos}

O experimento foi conduzido no Laboratório de Bioclimatologia Animal do Departamento de Zootecnia, do Centro de Ciências Agrárias da Universidade Federal de Viçosa, em Viçosa, Minas Gerais.

Foram utilizados 280 frangos de corte machos, da linhagem Cobb, previamente vacinados contra as doenças de marek e bouba aviária, mantidos em câmaras climáticas com temperatura do ar e umidade relativa controladas dos 22 aos 42 dias de idade. As câmaras climáticas foram ajustadas para manter a temperatura constante em $22^{\circ} \mathrm{C}$ e a umidade relativa entre 65 e $75 \%$.

Durante a fase inicial (1 a 21 dias de idade), as aves foram criadas em galpão convencional com ração contendo, por quilograma, $3.000 \mathrm{kcal}$ de EM e 21,8\% de PB, formulada para satisfazer as exigências nutricionais de aves nessa fase, conforme preconizado por Rostagno et al. (2005), e manejadas conforme descrito por Gomes et al. (1996).

No $22^{\circ}$ dia de idade, quando atingiram $856 \pm 6,48 \mathrm{~g}$, os frangos foram transferidos para as câmaras climáticas para o início do período experimental. As aves foram alojadas no interior das câmaras, em baterias metálicas com compartimentos de $0,85 \times 0,85 \mathrm{~m}$, providos de comedouro e bebedouro tipo calha.

As condições ambientais no interior das câmaras climáticas foram monitoradas e registradas diariamente, duas vezes ao dia ( 8 e 17 h), por meio de termômetros (de bulbo seco, bulbo úmido e de globo negro) mantidos no centro das salas. Os dados foram posteriormente convertidos em ITGU (índice de temperatura de globo e umidade) para caracterização do ambiente, conforme proposto por Buffington et al. (1981).

O programa de luz adotado durante o período experimental foi o contínuo (24 horas de luz artificial) utilizando-se lâmpadas fluorescentes de 75 watts por sala.

As aves foram distribuídas em delineamento inteiramente casualizado, com cinco tratamentos (níveis de proteína bruta da ração), oito repetições e sete aves por unidade experimental.

A ração basal (Tabela 1) foi formulada à base de milho e farelo de soja, suplementada com DL-metionina, L-lisina e suplemento de minerais e vitaminas para atender às exigências nutricionais das aves, segundo as recomendações de Rostagno et al. (2005). Os níveis de proteína bruta das rações experimentais foram obtidos por meio de ajustes nas quantidades de milho e farelo de soja. A qualidade aminoacídica da ração foi mantida por meio da suplementação dos aminoácidos metionina, treonina, valina, arginina e triptofano à medida que suas relações com a lisina digestível ficaram abaixo daquelas preconizadas por Rostagno et al. (2005), com base no conceito da proteína ideal. A água e a ração foram fornecidas à vontade, sendo a água trocada três vezes ao dia.

As aves foram pesadas no início e ao final do período experimental para a determinação do ganho de peso (GP). O consumo de ração (CR) foi calculado como a diferença entre 
Tabela 1 - Composições, centesimal e calculada, das rações experimentais

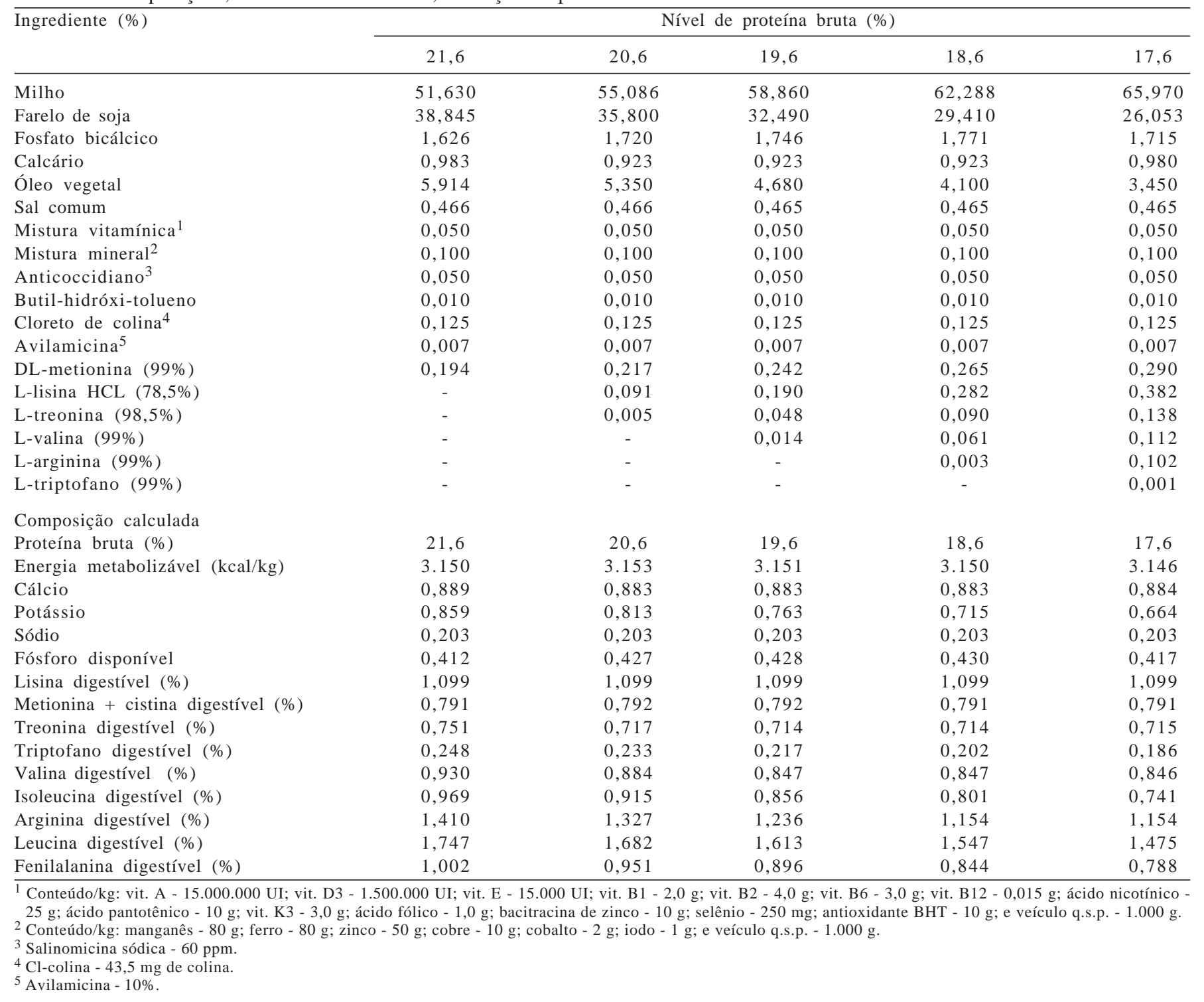

o total de ração fornecido e as sobras dos comedouros e do piso dos compartimentos. Com base no CR e no GP, calculou-se a conversão alimentar (CA).

Aos 42 dias de idade, as aves foram pesadas e três aves de cada unidade experimental, com pesos mais próximos da média da parcela experimental (10\% acima ou abaixo da média), foram abatidas após um período de jejum alimentar de 12 horas. Depois de sangradas, as carcaças foram depenadas, evisceradas e pesadas para avaliação do rendimento de cortes nobres (peito, coxa e sobrecoxa) determinados considerando-se o peso da carcaça.

As análises químicas das rações foram realizadas de acordo com metodologia descrita por Silva (1990), no Laboratório de Nutrição Animal do Departamento de Zootecnia da UFV.
As análises estatísticas foram realizadas utilizando-se o programa computacional SAEG - Sistema para Análises Estatísticas (UFV, 2001). Em caso de significância estatística, as médias foram comparadas pelo teste de Student-Newman-Keuls, a 5\% de probabilidade.

\section{Resultados e Discussão}

A temperatura interna da câmara manteve-se, durante todo o período experimental, em $21,6 \pm 0,7^{\circ} \mathrm{C}$, a umidade relativa em $74 \pm 4,0 \%$ e a temperatura de globo negro em $22,5 \pm 0,7^{\circ} \mathrm{C}$. O índice de temperatura de globo e umidade (ITGU) calculado no período foi de $70 \pm 0,9$. A temperatura de $21,6^{\circ} \mathrm{C}$ observada neste trabalho pode ser considerada de termoneutralidade, pois está no intervalo de 17,5 e $26,0^{\circ} \mathrm{C}$ estabelecido pelo manual da linhagem das aves utilizadas 
(Cobb, 2005) como faixa de termoneutralidade para esta categoria animal.

O ganho de peso (GP) das aves não foi influenciado $(\mathrm{P}>0,05)$ pela redução do nível de proteína bruta da ração (Tabela 2), resultado que está de acordo com os obtidos por Costa et al. (2001) que, avaliando o desempenho de frangos de corte de 22 a 42 dias de idade alimentados com rações contendo 17,$50 ; 18,00 ; 18,50 ; 19,00$ ou $19,50 \%$ de PB e suplementadas com aminoácidos industriais também não encontraram diferença no GP das aves entre os níveis de PB avaliados.

Este resultado corrobora também com os obtidos por Faria Filho (2003), que não observaram diferença no ganho de peso de frangos de corte alimentados com rações com 20,$0 ; 18,5$ ou $17,0 \%$ de $P B$, formuladas segundo o conceito de proteína ideal, e mantidos em ambientes com temperaturas de 20 ou $25^{\circ} \mathrm{C}$ de 21 a 42 dias de idade. De forma similar, Kolling et al. (2005) utilizando rações com 22,0; 20,0 ou $18,0 \%$ de PB e Tabeidian et al. (2005) com 18,4 ou $20,25 \%$ de $\mathrm{PB}$, formuladas para atender às exigências nutricionais descritas pelo NRC (1994), não encontraram influência dos níveis de PB avaliados no GP dos frangos de corte de 22 a 42 dias de idade.

Apesar de o GP não ter variado significativamente, a redução do nível de proteína bruta da ração de 21,6 para $17,6 \%$ promoveu redução de até 5,0\% no GP absoluto das aves. Este resultado pode indicar que a ração com menor nível de PB, mesmo suplementada com metionina, lisina, treonina, valina, arginina e triptofano digestíveis, pode ter ficado deficiente em algum outro aminoácido, prejudicando o desempenho das aves (Costa et al., 2001; Aftab et al., 2006). Segundo Lisboa et al. (1999), as respostas aos níveis de aminoácidos dependem do próximo aminoácido limitante. Em estudos realizados com pintos de corte, Dean et al. (2006) observaram que rações contendo $16,2 \%$ de PB, mesmo quando suplementadas com aminoácidos industriais para atender às exigências dessa categoria, proporcionaram menor GP em comparação à ração contendo o nível de PB recomendado (22,2\%). Entretanto, quando adicionada apenas glicina à ração contendo 16,2\% de PB, esses autores observaram ganho de peso similar ao obtido com a ração convencional $(22,2 \% \mathrm{~PB})$.

O consumo de ração (CR) não foi influenciado $(\mathrm{P}>0,05)$ pela redução do nível de PB da ração. Este resultado foi semelhante aos descritos por Sabino et al. (2004), que não observaram diferença nessa variável em frangos de corte alimentados com rações contendo 15,0; 17,0; 19,0; 21,0 ou 23,0\% de PB suplementadas com aminoácidos industriais em quantidades adequadas para o atendimento das exigências nutricionais das aves de 22 a 42 dias de idade. Similarmente, Faria Filho (2003) e Tabeidian et al. (2005) também não observaram influência dos níveis de proteína bruta no CR em frangos de corte de 22 a 42 dias de idade.

Contudo, os dados obtidos neste estudo diferem dos reportados por Aletor et al. (2000), que, avaliando o efeito da redução do nível de PB (22,5 para 15,3\%) em rações para frangos de corte suplementadas com aminoácidos industriais, observaram aumento no consumo de ração de 22 a 42 dias de idade, à medida que os níveis de PB foram reduzidos. Da mesma forma, diferem dos resultados obtidos por Costa et al. (2001), que observaram relação inversa entre os níveis de PB na ração e o consumo de ração pelas aves.

Alleman \& Leclercq (1997), em pesquisa com frangos de corte de 23 a 44 dias de idade, mantidos em ambiente termoneutro $\left(22^{\circ} \mathrm{C}\right)$ recebendo rações com 16,0 ou $20,0 \%$ de PB suplementadas com aminoácidos industriais, também observaram maior CR nas aves alimentadas com a ração com menor nível de PB.

As diferenças no CR freqüentemente descritas na literatura para aves alimentadas com rações suplementadas com aminoácidos industriais parecem estar relacionadas, entre outros fatores, ao grau de redução dos níveis de PB (Aletor et al., 2000) e à qualidade do perfil aminoacídico das rações (Gonzales, 2002). De acordo com Albino et al. (1999), o grau de deficiência ou de desequilíbrio de aminoácidos ocasiona reações variadas nas aves, alterando o consumo de ração.

Apesar de os resultados não terem diferido significativamente entre os níveis de PB avaliados, em valor absoluto, o consumo de ração entre as aves alimentadas com as rações com os mais baixos níveis de PB (18,6 e 17,6\%) foi,

Tabela 2 - Desempenho de frangos de corte mantidos em ambiente termoneutro e alimentados com rações com níveis reduzidos de proteína bruta de 22 a 42 dias de idade

\begin{tabular}{|c|c|c|c|c|c|c|}
\hline \multirow[t]{2}{*}{ Parâmetro } & \multicolumn{5}{|c|}{ Nível de proteína bruta (\%) } & \multirow[t]{2}{*}{$\overline{C V}(\%)$} \\
\hline & 21,6 & 20,6 & 19,6 & 18,6 & 17,6 & \\
\hline Ganho de peso (g) & 1978 & 1909 & 1853 & 1910 & 1879 & 5,55 \\
\hline Consumo de ração (g) & 3204 & 3207 & 3199 & 3346 & 3325 & 5,09 \\
\hline Conversão alimentar $(\mathrm{g} / \mathrm{g})^{1}$ & $1,62 \mathrm{c}$ & $1,68 \mathrm{bc}$ & $1,73 a b$ & $1,75 a$ & $1,77 \mathrm{a}$ & 3,26 \\
\hline
\end{tabular}

${ }^{1}$ Médias seguidas de letras diferentes na mesma linha diferem $(\mathrm{P}<0,01)$ entre si pelo teste SNK. 
em média, 4,1\% maior que o daquelas alimentadas com as rações com mais de 19,6\% de $\mathrm{PB}$.

A conversão alimentar (CA) nas aves alimentadas com a ração com $21,6 \%$ de $\mathrm{PB}$ foi melhor $(\mathrm{P}<0,01)$ que a obtida nas aves alimentadas com as rações com 19,6 a 17,6\% de PB. De forma similar, Oliveira (2002) observou piora na CA dos frangos de corte de 22 a 42 dias de idade, como resultado da redução gradativa de 22 para 17\% no nível de PB da ração suplementada com aminoácidos industriais utilizando o conceito de proteína ideal. Bartov \& Plavinik (1998), em estudo com frangos de corte de 7 a 42 dias e de 28 a 42 dias de idade alimentados com rações contendo 22,0 e 19,1\% de PB, mantendo as mesmas proporções de lisina e aminoácidos sulfurosos na PB, de acordo com o NRC (1994), verificaram melhor conversão alimentar para as aves que receberam ração com maior nível de $\mathrm{PB}$, mesmo não encontrando diferença no consumo de alimento e no ganho de peso. Resultados semelhantes também foram encontrados por Allerman \& Leclercq (1997), Aletor et al. (2000), Costa et al. (2001) e Sabino et al. (2004), que observaram melhora na conversão alimentar de frangos de corte com o aumento dos níveis de PB da ração.

Os resultados obtidos neste estudo diferem, no entanto, daqueles apresentados por Faria Filho (2003) e Tabeidian et al. (2005), que não observaram influência da redução do nível de proteína bruta da ração sobre a conversão alimentar das aves. As discrepâncias verificadas entre os resultados encontrados na literatura podem estar relacionadas às diferenças na especificidade dos aminoácidos suplementados nas rações com baixo nível de $\mathrm{PB}$, às linhagens genéticas utilizadas ou às fases de vida das aves avaliadas (Kerr \& Kidd, 1999a; Swennen et al., 2006).

O peso absoluto de carcaça não foi influenciado $(\mathrm{P}>0,05)$ pela redução da proteína bruta da ração (Tabela 3), o que confirma os resultados descritos por Tabeidian et al. (2005), que também não encontraram influência dos níveis de proteína bruta da ração sobre os pesos de carcaça de frangos de corte aos 49 dias de idade. Por outro lado, este resultado difere dos encontrados por Moran Jr. et al. (1992) e Kolling et al. (2005), que encontraram menor peso absoluto de carcaça em frangos alimentados com rações contendo baixos níveis de PB.

Os níveis de proteína bruta da ração também não influenciaram $(\mathrm{P}>0,05)$ o peso absoluto de peito. Este resultado não está consistente com os encontrados por Kolling et al. (2005) que verificaram menor peso de peito em frangos alimentados com rações com teor de PB inferior a 20,0\%. Por outro lado, este resultado está de acordo com Alleman \& Leclercq (1997) que, avaliando o efeito de dois níveis de PB (16,0 e 20,0\%) em rações suplementadas com aminoácidos industriais, também não observaram diferenças no peso absoluto do peito de frangos de corte aos 44 dias de idade. Segundo esses autores, a redução do teor de PB da ração não altera significativamente o peso do peito quando os aminoácidos essenciais são suplementados em níveis suficientes para atender as exigências nutricionais das aves.

Os pesos absolutos de coxa e sobrecoxa também não foram influenciados $(\mathrm{P}>0,05)$ pela redução do nível de $\mathrm{PB}$ da ração. Resultado semelhante foi relatado por Lisboa et al. (1999) que, avaliando o efeito de diversos teores de PB (16,5; 18,0; 19,5 e 21,0\%) na ração de frangos de corte de três linhagens, de dos 22 aos 42 dias de idade, não encontraram efeito dos níveis de PB sobre os pesos absolutos de coxa e sobrecoxa de nenhuma das linhagens. Kolling et al. (2005) também não encontraram efeito dos níveis de proteína bruta da ração sobre o peso de perna (coxa+sobrecoxa) de frangos.

A redução da proteína bruta das rações não influenciou $(\mathrm{P}>0,05)$ o peso relativo de peito, resultado que difere dos encontrados por Costa et al. (2001), que constataram redução linear no rendimento de peito à medida que diminuíram o nível de PB da ração. Este resultado difere também dos

Tabela 3 - Peso absoluto de carcaça e pesos absoluto e relativo de cortes nobres (peito, coxa e sobrecoxa) de frangos de corte de 22 a 42 dias de idade mantidos em ambiente termoneutro e alimentados com rações com níveis reduzidos de proteína bruta

\begin{tabular}{|c|c|c|c|c|c|c|}
\hline \multirow[t]{2}{*}{ Parâmetro } & \multicolumn{5}{|c|}{ Nível de proteína bruta (\%) } & \multirow[t]{2}{*}{ CV (\%) } \\
\hline & 21,6 & 20,6 & 19,6 & 18,6 & 17,6 & \\
\hline & \multicolumn{5}{|c|}{ Peso absoluto (g) } & \\
\hline Carcaça ${ }^{N S}$ & 2120 & 2107 & 2105 & 2116 & 2088 & 6,35 \\
\hline Peito $^{N S}$ & 696 & 707 & 705 & 701 & 703 & 8,66 \\
\hline $\mathrm{Coxa}^{\mathrm{NS}}$ & 276 & 269 & 267 & 266 & 262 & 7,64 \\
\hline \multirow[t]{2}{*}{ Sobrecoxa ${ }^{\text {NS }}$} & 291 & 285 & 283 & 286 & 278 & 10,64 \\
\hline & \multicolumn{5}{|c|}{ Peso relativo (\%) } & \\
\hline Peito $^{\text {NS }}$ & 32,80 & 33,54 & 33,11 & 33,67 & 34,12 & 4,71 \\
\hline $\mathrm{Coxa}^{\mathrm{NS}}$ & 13,00 & 12,79 & 12,69 & 12,60 & 12,53 & 5,26 \\
\hline Sobrecoxa ${ }^{\text {NS }}$ & 13,76 & 13,57 & 13,42 & 13,54 & 13,29 & 9,94 \\
\hline
\end{tabular}

NS Não-significativo a 5\% de probabilidade pelo teste de SNK. 
relatos de Leeson (1995) e Bartov \& Plavinik (1998) de que o rendimento de peito aumenta de acordo com a ingestão de proteína bruta. Por outro lado, os resultados deste estudo estão consistentes com os obtidos por Alleman \& Leclercq (1997), Oliveira (2002) e Sabino et al. (2004), que não observaram diferenças nesse parâmetro quando variaram o nível protéico das rações.

Os rendimentos de coxa e sobrecoxa não foram influenciados $(\mathrm{P}>0,05)$ pela redução dos níveis de $\mathrm{PB}$ da ração. Resultados semelhantes foram verificados por Kerr \& Kidd (1999a,b) e Oliveira (2002), que não observaram influência dos diferentes níveis de PB sobre os mesmos parâmetros. Da mesma forma, corroboram os resultados descritos por Laganá et al. (2007), que também não observaram influência dos níveis de PB da ração sobre os rendimentos de coxa e sobrecoxa de frangos de corte dos 21 aos 42 dias de idade. Entretanto, Moran Junior et al. (1992) observaram que o peso relativo de coxa, diferente do peso relativo de sobrecoxa, foi maior em frangos alimentados com rações com baixo teor de proteína bruta.

\section{Conclusões}

A redução do nível de proteína bruta da ração de 21,6 para 17,6\%, com suplementação de aminoácidos industriais, frangos de corte na fase de crescimento mantidos em ambiente termoneutro, piora a conversão alimentar, mas não influencia as demais características de desempenho e de carcaça estudadas.

\section{Referências}

AFTAB, U.; ASHRAF, M.; JIANG, Z. Low protein diets for broilers. World's Poultry Science Journal, v.62, p.688-698, 2006.

ALBINO, L.F.T.A.; SILVA, S.H.M.; VARGAS, J.G. et al. Níveis de metionina + cistina para frangos de corte de 1 a 21 e 22 a 42 dias de idade. Revista Brasileira de Zootecnia, v.28, p.519-525, 1999.

ALETOR, V.A.; HAMID, I.I.; NIESS, E. et al. Low-protein amino acid-supplemented diets in broiler chickens: Effect on performance, carcass characteristics, whole body composition and efficiencies nutrient utilization. Journal Science Food Agriculture, v.80, p.547-554, 2000.

ALLEMAN, F.; LECLERCQ, B. Effects of dietary protein and environmental temperature on growth performance and water consumption of male broiler chickens. British Poultry Science, v.38, p.607-610, 1997

BARTOV, I.; PLAVNIK, I. Moderate excess of dietary protein increases breast meat yield of broiler chicks. Poultry Science, v.77, p.680-688, 1998.

BUFFINGTON, D.E.; COLLASSO-AROCHO, A.; CANTON, G.H. et al. Black globe-humidity index (BGHI) as comfort equation for dairy cows. Transaction of the American Society of Agricultural Engineering, v.24, p.711-714, 1981.

COBВ. Guia de manejo para frangos de corte cobb 500. S.I.: s.n., 2005. 58p.
CORZO, A.; FRITTS, C.A.; KIDD, M.T. et al. Response of broiler chicks to essential and non-essential amino acid supplementation of low crude protein diets. Animal Feed Science and Technology, v.118, p.319-327, 2005.

COSTA, F.G.P.; ROSTAGNO, H.S.; ALBINO, L.F.T. et al. Níveis dietéticos de lisina para frangos de corte de 1 a 21 e 22 a 40 dias de idade. Revista Brasileira de Zootecnia, v.30, p.1490-497, 2001.

DEAN, D.W.; BIDNER, T.D.; SOUTHERN, L.L. Glycine supplementation of low protein, amino acid-supplemented diets supports equal performance of broiler chicks. Poultry Science, v.85, p.288-296, 2006

DESCHEPPER, K.; DE GROOTE, G. Effect of dietary protein, essential and nonessential amino acids on the performance and carcass composition of male broiler chickens. British Poultry Science, v.36, p.229-245, 1995.

FARIA FILHO, D.E. Efeito de dietas com baixo teor protéico, formuladas usando o conceito de proteína ideal, para frangos de corte criados em temperaturas fria, termoneutra e quente. 2003. 93f. Dissertação (Mestrado em Zootecnia) Faculdade de Ciências Agrárias e Veterinárias/Universidade Estadual Paulista, Jaboticabal.

FARIA FILHO, D.E.; ROSA, P.S.; FIGUEIREDO, D.F. et al. Dietas de baixa proteína no desempenho de frangos criados em diferentes temperaturas. Pesquisa Agropecuária Brasileira, v.41, p.101-106, 2006.

GOMES, P.C.; ALBINO, L.F.T.; SILVA, M.A. Criação de frangos de cortes. Informe Técnico. Viçosa, MG. Ano 17, 1996. 18p.

GONZALES, E. Ingestão de alimentos: mecanismos regulatórios. In: MACARI, M.; FURLAN, R.L.; GONZALES, E. (Eds.). Fisiologia aviária aplicada a frangos de corte. 2.ed. Jaboticabal: FUNEP, 2002. p.187-199.

KERR, B. J.; KIDD, M.T. Amino acid supplementation of lowprotein broiler diets: 1 . Glutamic acid and indispensable amino acid supplementation. Journal of Applied Poultry Research, v.8, p.298-309, 1999a.

KERR, J.B.; KIDD, M.T. Amino acid supplementation of low protein broiler diets 2. Formulation on the ideal amino acid basis. Journal of Applied Poultry Research, v.8, p.310-320, 1999b.

KOLLING, A.V.; KESSLER, A.M.; RIBEIRO, A.M.L. Desempenho e composição corporal de frangos de corte alimentados com diferentes níveis de proteína e de aminoácidos ou com livre escolha das dietas. Revista Brasileira de Zootecnia, v.34, p.98-103, 2005.

LAGANÁ, C.; RIBEIRO, AM.L.; KESSLER, AM. et aI. Effects of the reduction of dietary heat increment on the performance, carcass yield, and diet digestibility of broilers submitted to heat stress. Brazilian Joumal of Poultry Science, v.9, p.45-51, 2007.

LEESON, S. Nutrição e qualidade da carcaça de frangos de corte. In: CONFERÊNCIA APINCO DE CIÊNCIAS E TECNOLOGIA AVÍCOLAS, 1995, Curitiba. Anais... Campinas: Fundação APINCO de Ciência e Tecnologia Avícolas, 1995. p.111-118.

LISBOA, J.S.; SILVA, D.J.; SILVA, M.A. et al. Rendimento de carcaça de três grupos genéticos de frangos de corte alimentados com rações contendo diferentes teores de proteína. Revista Brasileira de Zootecnia, v.28, p.548-554,1999.

MACARI, M. Estresse de calor em aves. In: REUNIÃO ANUAL DA SOCIEDADE BRASILEIRA DE ZOOTECNIA, 38., 2001, Piracicaba. Anais... Piracicaba: Fundação de Estudos Agrários "Luiz de Queiroz", 2001. p.686-716.

MENDONZA, M.O.B.; COSTA, P.T.C.; KATZER, L.H; et al. Desempenho de frangos de corte, sexados, submetidos a dietas formuladas pelo conceito de proteína bruta versus proteína ideal. Ciência Rural, v.31, p.111-115, 2001.

MORAN, JR., E.T.; BUSHONG, R.D.; BILGILI, S.F. Reducing dietary crude protein for broilers while satisfying aminoacids requirements by least-cost formulation: live performance, litter composition and yield of fast food carcass cuts at six weeks. Poultry Science, v.71, p.1687-1694, 1992. 
NATIONAL RESEARCH COUNCIL - NRC. Nutrients requirements of poultry. 9.ed. Washington D.C.: National Academic Press, 1994. 155p.

OLIVEIRA, C.J.P. Exigência nutricional em proteína bruta para frangos. 2002. 56f. Dissertação (Mestrado em Zootecnia) - Universidade Federal Rural de Pernambuco, Recife.

ROSTAGNO, H.S.; ALBINO, L.F.T.; DONZELE, J.L. et al. Tabelas brasileiras para aves e suínos: composição de alimentos e exigências nutricionais. 2.ed. Viçosa, MG: UFV, Departamento de Zootecnia, 2005. 186p.

SABINO, H.F.N.; SAKOMURA, N.K.; NEME, R. et al. Níveis protéicos na ração de frangos de corte na fase de crescimento. Pesquisa Agropecuária Brasileira, v.39, p.407-412, 2004.

SILVA, D.J. Análise de alimentos: métodos químicos e biológicos. Viçosa, MG: UFV, Imprensa Universitária, 1990. 165p.

SILVA, Y.L.; RODRIGUES, P.B.; FREITAS, R.T.F. et al. Redução de proteína e fósforo em rações com fitase para frangos de corte no período de 1 a 21 dias de idade. Desempenho e teores de minerais na cama. Revista Brasileira de Zootecnia, v.35, p.840-848, 2006.

SIQUEIRA, J.C.; OLIVEIRA, R.F.M.; DONZELE, J.L. et al. Níveis de lisina digestível da ração e temperatura ambiente para frangos de corte em crescimento. Revista Brasileira de Zootecnia, v.36, p.2054-2062, 2007.

SUIDA, D. Formulação por proteína ideal e conseqüências técnicas econômicas e ambientais. In: SIMPÓSIO INTERNACIONAL DE NUTRIÇÃO ANIMAL: Proteína ideal, energia líquida e modelagem, 2001, Santa Maria. Anais... Santa Maria: Empresa Brasileira de Pesquisa Agropecuária, 2001. p.27-43.

SWENNEN, Q.; JANSSENS, G.P.J.; COLLIN, A. et al. Diet-induced thermogenesis and glucose oxidation in broiler chickens: influence of genotype and diet composition. Poultry Science, v.85, p.731-742, 2006.

TABEIDIAN, A.; SADEGHI, G.H.; POURREZA, J. Effect of Dietary Protein Levels and Soybean Oil Supplementation on Broiler Performance. International Journal of Poultry Science, v.4, p.799-803, 2005.

TEMIM, S.; CHAGNEAU, A.M.; GUILlaummin, S. et al. Does excess dietary protein improve growth performance and carcass characteristic s in heat-exposed chickens. Poultry Science, v.78, p.312-317, 2000.

UNIVERSIDADE FEDERAL DE VIÇOSA - UfV. Manual de utilização do programa SAEG (Sistemas de Análises Estatísticas e Genéticas). Viçosa, MG, 2001. 301p. 